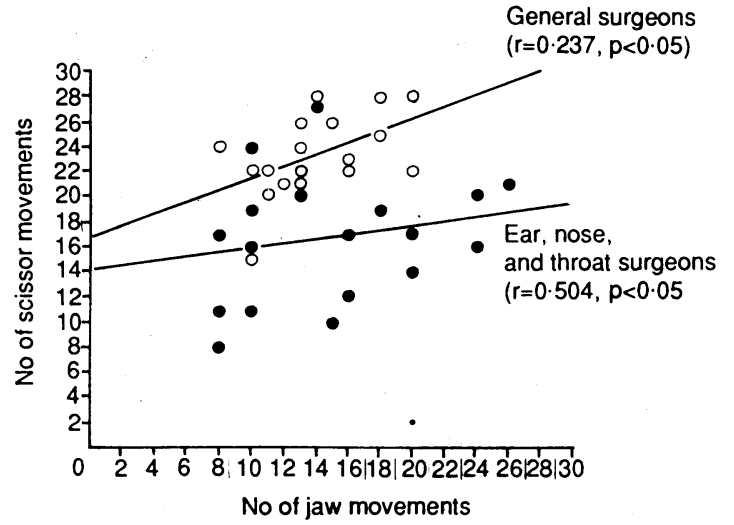

FIG 3-Number of cycles of SFR per 10 minute operation period in general surgeons $(O)$ and ear, nose, and throat surgeons $(\bullet)$

each surgical subspecialty but most developed in general surgeons and least developed in ear, nose, and throat surgeons (fig 3). Interestingly, analysis of values obtained early in the study indicated that ear, nose, and throat surgeons who trained as general surgeons have a more highly developed reflex than those who went straight into ear, nose, and throat surgery (not significant).

Although the exact neurological pathways are poorly understood, jaw activity and scissor opening and closing are directly correlated. The aim of this paper was not merely to describe a new reflex, interesting though this may be, but to explore potential practical applications. We believe that stimulating jaw activity will lead to increased opening and closing of the scissors. This may be more simply stated as increased productivity. It is therefore beholden upon anaesthetists in particular (but other members of the operating staff can each play their part) to encourage surgeons to maximise jaw activity. This involves engaging them in conversation and encouraging them to speak. We have found that surgeons enjoy explaining their work, particularly if prompted by the remark that other surgeons do a particular procedure in another way. In our experience, however, the topic is not important, but rather the intensity of the speech elicited-local hospital politics or even the newspaper crossword will suffice. The important thing is to stimulate speech. We are, after all, working in a theatre.

\title{
Can orthopaedic surgeons walk on water?
}

\section{S Barrett}

James Bond might make a good orthopaedic surgeon. His good looks and dynamic personality, essential in orthopaedics, are complemented by the ability to walk on water (or rather waterski on his bare feet as seen in his most recent film). To waterski barefoot requires skill and a large amount of nerve. In order to allow the water to support the body weight on the area of the feet, some $65 \mathrm{~cm}^{2}$, the tow boat must travel at $45 \mathrm{mph}$ Water is awfully hard at $45 \mathrm{mph}$. Because of this and because of the spectacular amounts of spray produced "barefooting" is perceived as a macho specialty among waterskiers. Nevertheless, I wanted to prove that orthopaedic surgeons could walk on water in addition to their other Bond-like qualities.

At the crack of dawn, when the water was at its most calm, the ordeal began. I was duly dragged up and down the lake five times at unimaginably high speeds until at last I stood on the surface. I felt bruised all over, although I wore two wetsuits to protect myself against the battering of the water.

Experienced barefoot skiers start lying supine in the water. As the speed increases they ski on their back and roll forward to ski on the buttocks. At approximately $45 \mathrm{mph}$ they place their feet on the water surface and stand up. Barefoot waterskiing has its share of tragic cases of spinal cord injury. Classically this occurs as the skier puts his feet down on the water, but pivots forward to overbalance hitting the water at great speed with the cervical and lumbar spine hyperextended. ${ }^{12} \mathrm{~A}$ more common injury may occur at the critical phase of skiing on the buttocks. At this stage the perineum is buffeted by water at $40 \mathrm{mph}$. Sudden catastrophic failure of wetsuit stitching under such trauma results in high speed rectal or vaginal enemas or both. There is a recognised incidence of rectal and vaginal tears and salpingitis. ${ }^{34}$ The misery of sudden wetsuit failure is instant, all pervading, and complete. Male barefooters wear a cricketer's box to protect the scrotum. This vital detail was learnt to my cost only after my attempts at barefooting.

I suffered a complication as yet undescribed in waterskiing-that of myoglobinuria after massive muscle trauma.

\section{Log rolled out of bed}

The following day, Monday, experiencing a little stiffness in the abdominal musculature, it became necessary to ease my legs by sitting down on the orthopaedic ward round. The next day the stiffness was such that I had to be log rolled out of bed. The ward round was conducted at a snail's pace to the undisguised mirth of my senior house officer, who, the previous day, had endured prolonged stories of my heroic exploits on the water. I began to produce scanty amounts of port coloured urine, positive for myoglobin. Terrified, I contacted a colleague in nephrology to be told to drink five litres of water a day. He raised the possibility of acute tubular necrosis and a period of dialysis should my renal function deteriorate.

On Wednesday I was due to operate all day. Complex telephone negotiations ensured that my senior house officer met me at the car to lever me out. The list that followed was vastly entertaining. Too weak and sore to lift the heavier orthopaedic instruments, I had to leave my assistant to do all the hammering and manipulating. The enormous fluid intake occasioned repeated trips to the lavatory during cases, anxiously recording the colour of my urine. Putting on a heavy lead apron for radiographic screening caused me to crumple to the floor where I remained until rescued by nursing staff.

Thursday brought a new problem. Weak as a kitten, I could hardly support the weight of my now hugely swollen scrotum, enlarged because of the pummelling of the water and the oedema from the torn muscles in the chest and abdominal wall. In what was now an established ritual, my senior house officer met me at the car again to help me out, but declined to act as a scrotal support. The twin problems of a massively swollen scrotum and being unable to stand up straight 


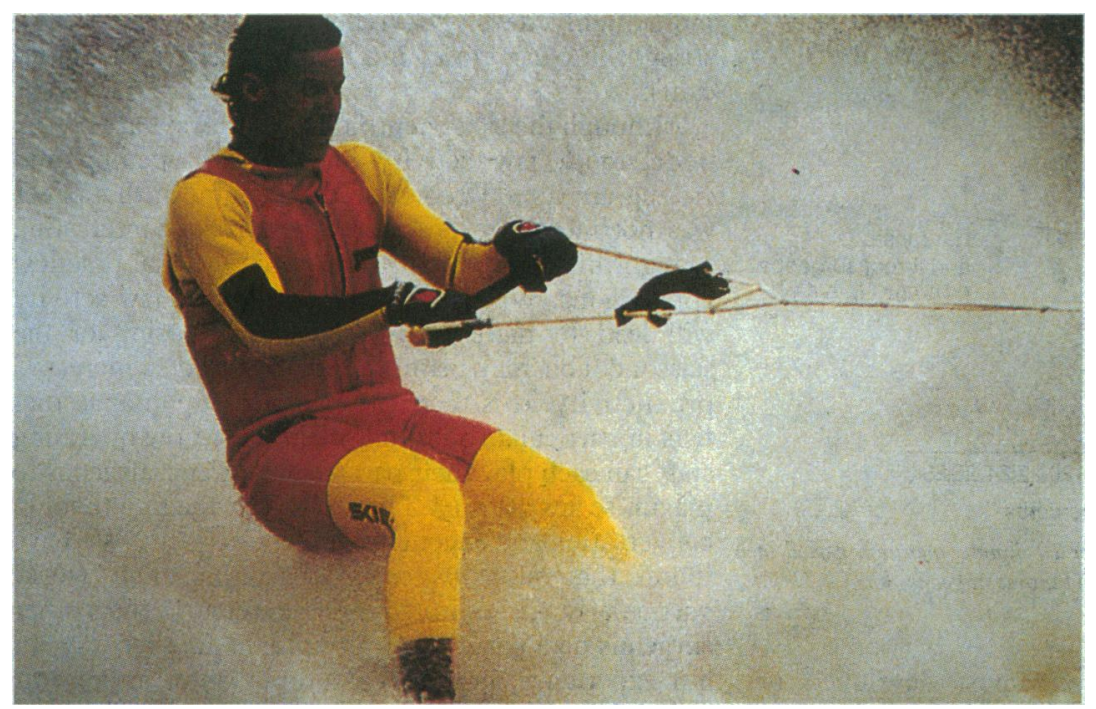

Elementary barefoot waterskiing

caused a tottering, wide based gait inclined forward at 20 degrees during rare periods of ambulation. I resembled someone who had just got off his horse walking into a force eight gale.

\section{Massive muscle breakdown}

Tests of renal function were taken four days after the incident. All electrolyte concentrations were normal, but the measurements of muscle breakdown aspartate transaminase and creatinine kinase were 1540 IU/l (normal 2-40 IU/l) and $45860 \mathrm{IU} / 1$ (normal < $170 \mathrm{IU} / \mathrm{l}$ ) respectively, indicating massive muscle breakdown. Death from acute tubular necrosis because of traumatic myolysis has resulted following concentrations of creatinine kinase as low as $3500 \mathrm{IU} / \mathrm{l}^{5}$ The creatinine clearance as a result was $148 \mathrm{ml} / \mathrm{min}$.

Friday saw some recovery as I was now able to stand unsupported for up to five minutes at a time. The urine had returned to a normal colour and I was able to put my socks on (with difficulty).

I had clearly "pulled" a large mass of muscles in my chest, shoulders, and abdomen caused by my strenuous efforts to stand on the water and the prolonged high speed battering while' in the water. Massive release of myoglobin occurred as it does in the crush syndrome,${ }^{6}$ and there was a risk of blocking the glomerulus of the kidney with the sequelae of acute tubular necrosis. Fortunately, this was avoided. This potentially severe injury has not been previously reported in barefoot waterskiing yet is a real possibility given the speed and trauma that the torso suffers as it is pulled through the water. Adequate body protection must be worn and repeated exposure to many high speed attempts should not be permitted.

Doctors are often accused of playing God in their dealings with patients. This is one orthopaedic surgeon who will no longer attempt to walk on water.

1 McCarthy GF. Hazards of waterskiing. Med f Aust 1969;1(9):481

2 Paterson DC. Waterskiing injuries. Practitioner 1971;206:655.

3 Morton DC. Gynaecological complications of waterskiing. Med f Aust 1970;1(25): 1256 .

4 Ramey JR. Intrarectal tear with bleeding from a waterskiing accident. f Fla Med Assoc 1974;61:162.

5 Lonka L, Pedersen RS. Fatal rhabdomyolysis in a marathon runner. Lance 1987;ii:857.

6 Bywaters EGL, Beall D. Crush injuries with impairment of renal function. BMf 1941;i:427.

\title{
Diet, diabetes, and male chauvinism
}

\author{
C S J Probert, W Maddison, J M Roland
}

We have suspected that diabetic men receive more support from their wives than diabetic women get from their husbands. Patients attending our diabetic clinic are often accompanied by their spouses. Patients' wives often contribute to dietary histories and tend to say "our diet" and "we eat," suggesting that diabetic men and their wives eat the same food. We report an investigation of the effect of diabetes on the diet of the patients' spouses.

\section{Patients, methods, and results}

We asked 58 consecutive married patients attending our diabetic clinic to complete a questionnaire and requested that they ask their spouse to complete an identical questionnaire. Patients whose spouses were diabetic or ate other "special" diets were excluded. Age and sex matched controls were recruited from a general medical clinic in a similar manner.

The questionnaire required the subject to tick a box against a food item if he or she ate it at home or elsewhere. A total of 63 items containing varying amounts of sugar, fibre, and fat were arranged at random.

The analysis compared the number of items that couples chose differently. The discordant items were counted to give a discordance score for couples in whom the woman was diabetic and for those in whom the man was diabetic and for their corresponding control couples. These scores were compared by Student's $t$ test.
In all, 56 control questionnaires were returned; 51 were complete. They were matched with completed case replies ( 28 diabetic men and 21 diabetic women). The cases and controls were well matched for age (age range $31-73$ for diabetic men, 28-74 for controls, SD 2.6 years; age range $26-73$ for diabetic women and controls, SD $4 \cdot 1$ years). Fifteen men and 15 women were receiving insulin. The discordance scores for couples in which the woman was diabetic were compared with those in control couples $(t=3 \cdot 2$, $\mathrm{p}<0.001$ ) and the scores of couples in which the man was diabetic were compared with those in control couples $(t=0 \cdot 46, \mathrm{NS})$ (table).

Mean (SD) discordance scores with respect to food items eaten by couples in whom the man or woman was diabetic and their matched control couples

\begin{tabular}{lcc}
\hline & Case couples & Control couples \\
\hline Man & $13 \cdot 8(7 \cdot 0)$ & $13 \cdot 0(6 \cdot 1)$ \\
Woman & $17 \cdot 0(7 \cdot 4)$ & $10 \cdot 6(5 \cdot 5)$ \\
\hline
\end{tabular}

Scrutiny of the questionnaires satisfied us that the similarity in the couple's diet in the diabetic man's home is because both members are eating "diabetic" diets.

Retrospective analysis of the attendance at our diabetic support and discussion group over 10 months showed that diabetic men were more likely to be accompanied to the groups by their spouse than were diabetic women (63/77 men compared with $12 / 70$ 